\title{
En Erken Devirlerden Türk Mezarlarına Ölü Yakımı Uygulaması
}

\section{Cremation from the Earliest Periods to Turkic Graves}

\author{
Dr. Öğr. Üyesi Elvin YILDIRIM
}

$\ddot{\mathbf{O z}}$

Türklerin binlerce yıllık mezar gömü üslubu olarak inhumasyon uygulamasını kullandıkları, atalar kültü inanışına göre ölülerini kurganlara gömdükleri bilinmektedir. Diğer taraftan Türkler arasında ölü yakımının uygulanıp uygulanmadığı meselesi üzerine tartışmalar mevcuttur. Çin kaynakları Türklerin ölü yakımı uygulamasını yaptıklarını ifade etmektedirler. Arkeolojik olarak da Türklerde ölü yakımı uygulamasının kullanıldığı görülmektedir. Böylece yazılı kaynaklar ve maddi kültür unsurları birbirlerini desteklemiş bulunmaktadır. Türklerin yurt tuttuğu engin bozkır coğrafyasında Ural havalisinden Hakasya topraklarına kadar Srubna-Andronovo Külttürü döneminden Karasuk Kültürü ve Tagar-Taştık Kültürü ve beraberinde Türk boylarının sahneye çıkışı ve uyguladıkları ölü gömme uygulamalarını mezar envanterleri üzerinden inceleyerek, kremasyon uygulamasının en erken hangi dönem kullanıldığının ve ne zaman terk edildiğinin cevaplarını ortaya koymaya çalışacağız.

Anahtar Kelimeler: Kremasyon, inhumasyon, Türkler, ritüel, Andronovo

Makale Türü: Araştırma

\begin{abstract}
It is known that Turks used inhumation as a burial style for thousands of years and buried their dead to kurgans according to ancestor cult belief. On the other hand, there is controversy among researchers that whether the Turks practiced the cremation (which is another ritual) or not. Written sources state that Turks were practicing cremation. Cremation is seen in Turks according to archaeological studies. Thus, written sources and material culture elements supported to each other. From the period of Srubna-Andronovo Culture to Karasuk Culture and Tagar-Tashtik Culture in the vast steppe geography, where the Turks kept their homeland, from the Ural region to the Khakassia territory, the emergence of the Turkic tribes and the burial practices they applied and the cremation practices will be examined according to grave inventories.
\end{abstract}

Keywords: Cremation, inhumation, Turks, ritual, Andronovo

Paper Type: Research

${ }^{1}$ İstanbul Aydın Üniversitesi, Fen-Edebiyat Fakültesi, elvinyildirim@ aydin.edu.tr

Atıf için (to cite): Yıldırım, E. (2019). En erken devirlerden Türk mezarlarına ölü yakımı uygulaması. Afyon Kocatepe Üniversitesi Sosyal Bilimler Dergisi, 22(1), 28-37. 


\section{Giriş}

En erken devirlerden itibaren insanlar ölülerinin anısını yaşatmak adına defin merasimi geleneklerini uygulamışlardır. Bu gelenekler içerisinde inhumasyon ${ }^{2}$ uygulamaları ve kremasyon ${ }^{3}$ uygulamaları bulunmaktadır. Bu iki gelenek farklı toplumlar tarafından türlü şekilde uygulanmışlardır. Türkler yaygın olarak ölüyü değerli eşyaları ile birlikte doğrudan kurgan olarak adlandırılan höyük mezarlara gömmüşlerdir. Tarihi döneme göre bu kurgan tipi mezarlarda farklı uygulama yöntemleri kullanılmıştır. Bazı dönemlerde boyutları çok büyük kurganlar yapılmış, bazen de yapılan mezarların hem çaplarında hem de höyük yüksekliğinde küçülme gözlenmiştir. Bölgeden bölgeye kurgan ve mezarların yapımında kullanılan malzemelerde farklılıklar gözlenmiştir. Orman sıklığının geniş olduğu sahalarda kütük mezar kabirleri yapılırken, ağaç bakımından fakir bölgelerde ise geniş levha şeklinde granit ve şist tipi kayalardan mezar odaları kurulmuştur. Kimi kurganların höyükleri taş ve kayalarla yükseltilirken, kimi kurganlar höyük bakımından zayıf ve alçak düzenlenmişlerdir.

Bununla birlikte Türklerde farklı mezar gömü uygulamalarına tesadüf edilmektedir (Çoruhlu, 2004, s. 244-268): doğrudan gömme, mumyalayarak gömme, kremasyona tabi tutma vb. gibi. Türk mezar gömü üslubunda mumyalama uygulamasının bulunması oldukça dikkat çekicidir. Bu uygulamanın misallerine İskitler döneminde Altaylarda bulunan Pazırık (Durmuş, 2004, s. 23; Heredotos, IV, s. 220; Ögel, 2003, s. 63) kurganlarında ve İskitler dönemine ait diğer kurgan gruplarında, Hun kurganlarında (Karamürsel, 2002, s. 78; Ögel, 2004, s. 64) ve hatta Koş Agaç-JanaAul' daki (Hudyakov ve Koçaev, 1997, s. 11) Türk mezarlarında tesadüf edilmiştir. Mumyalama tekniğinin İslam'ın kabulünün ardından nadir de olsa Anadolu Selçukluları ve Beylikler döneminde de kullanıldığ 1 görülmektedir (Karamürsel, 2002, s. 78). İnhumasyon ve mumyalama dışında Yakut Türklerinde görülen ve 19. yy'a kadar devam ettirilen ölülerin ağaçlar üzerine, arangasa (Duranlı, 2018, s. 208) konulması uygulaması da oldukça dikkat çekicidir. Fakat en yaygın şekilde Türkler mezar gömü üslubu olarak ölülerini mezar çukuruna doğrudan gömme/inhumasyon uygulamışlar ve mezar üstünü bir höyük ile kapatmışlardır. Bu uygulamalar miladi X-XI. yy'da dahi Türkler arasında tatbik edilmiş, İbni Fazlan, İbni Rüsteh, Mervezi ve Gerdizi gibi Arap müelliflerin eserlerinde hatta Bizans kaynaklarından Theophylaktos Simokatta'da ayrıntıları ile zikredilmiştir (İbn Fazlan Seyahatnamesi, 1995, s. 40; Roux, 2011, s. 3; Şeşen, 2001, s. 174, Marvazi:33) ${ }^{4}$.

\section{Yöntem}

En erken Devirlerden Türk Mezarlarına Ölü Yakımı başlıklı çalışmamızda hem arkeologların kazı çalışmaları sonrası yaptıkları çalışmalar hem de onların elde ettikleri bulgular üzerine tarihçilerin ve diğer bilim adamlarının yaptıkları araştırma eserleri incelenmiştir. Bu bakımdan çalışma Neolitik dönemden Tunç Çağı ve Demir Çağına ve Türklere kadar olan geniş bir zaman aralığını kapsamakta ve bu dönemlere ait ölü yakımı uygulamaları üzerine arkeolojik kazılarda elde edilen buluntuların değerlendirilmesi ve konu üzerine görüşlerin neler olduğunu tespit etmeye yönelik bir çalışma olmuştur. Çok erken dönemlerden itibaren bir gelenek olarak sürdürülen ölü yakımı uygulamasının Türkler arasında da kullanıldığı kaynaklara ve arkeolojik buluntulara göre tespit edilmiştir.

Türk mezar gömü üslubu olarak tatbik edilmiş bir diğer uygulama ise ölü yakımı/kremasyon sonras1 gömmedir. Kremasyon ölümden sonraki yaşamla ilişkilendirilmektedir. Buna göre yeryüzüne bağlı kalan fiziksel kalıntılar kül şeklinde gökyüzüne yükselir ve orada bulunmaya devam ederdi (Binford, 1971, s. 12). Çin kaynaklarında

\footnotetext{
2 Ölünün beden bütünlüğünün korunarak gömülmesi.

${ }^{3}$ Ölünün bedeninin yakılması uygulaması.

${ }^{4}$ Ayrıca tarihi kaynaklardaki ölü yakımı uygulamaları ve ateş kültü ile ilgi ayrıntılı bilgi için bkz. Recep Yaşa, "Eski Türk Cenaze Törenlerinde Ölü Yakma Âdeti”, Türk Tarihi Araştırmaları Dergisi/Journal Of Turkish History Researches, Prof. Dr. Bahaeddin Ögel Sayıs1, Y11/Vol.4, Sa/No.1, Bahar/Spring 2019, s. 275-295.
} 
Göktürklerin ölü gömme ritüelleri arasında kremasyon uygulaması zikredilmiştir fakat bu uygulama ne kadar yaygın idi veya her ölünün bedeni yakılır mıydı? sorularının cevabını sadece arkeolojik çalışmalar verebilmekte fakat bazı durumlarda meselelere net bir açıklama getirememektedirler. Bu uygulamanın varlığı hem yazılı kaynaklar hem de arkeolojik kazılarla ortaya konulmuş olmasına rağmen ilim adamları tarafından farklı görüşler ortaya konulmuştur.

Mezarlar kavimlerin ve daha sonraki dönemlerdeki halkların tarihlerini araştırma konusunda vazgeçilmez kaynaklardır. Bu kaynaklar aracılı̆̆ı ile etnik gruplar arasındaki farklılıklar ortaya konulmakta ve söz konusu etnik grupların özellikleri belirlenebilmektedir. Rudenko, mezarların etnik meseleleri aydınlatmasının önemini ifade ettikten sonra, "mezarlara her zaman belirleyici bir unsur olarak bakılmaması gerektiğini çünkü kavimlerin gelişme sürecinde bazen köklü değişiklikler gerçekleşebileceğini, defin merasiminin bundan etkilenmese bile şartlara göre ayn dönemde farklı defin şekillerinin gerçekleşebileceğini" ifade etmektedir (Rudenko, 1952, s. 33). Bu duruma göre aynı soydan gelen, aynı dili konuşan, aynı kültüre sahip milletler yaşadıkları süreçte farklı sebeplerle mezar gömü geleneklerinde farklılığa gidebilirlerdi. Kronolojik açıdan aynı döneme ait mezarlarda inhumasyon uygulaması uygulanırken karbon testleri ile aynı döneme ait olduğu belirlenen mezarlarda kremasyon yapıldığı da tespit edilmiştir. Neden farklı uygulamalara gidildiği hakkında tam olarak konuşmak doğru olmayacaktır. Fakat ölü yakımının uygulandığı mezarların belli bir kesime uygulandığına dair görüşler de mevcuttur.

Hudyakov ve Tabaldiyev eski Türklere ait mezarlarda ölü yakımı uygulamasının tamamen kabul edilemeyeceğini, bunun için daha fazla veriye ihtiyaç olduğunu ifade etmişlerdir. Bununla birlikte M. P. Gryaznov, L. N. Gumilev, L. P. Potapov ve A. S. Surazakov gibi ilim adamları Türklerdeki kremasyon uygulamasının varlığını desteklemişlerdir (Hudyakov ve Tabaldiyev, 2009, s. 23) $)^{5}$. Türklerin bu uygulamayı kullandıkları apaçık ortada olsa da (Biçurin, 1950, s. 230), Muzio, Türklerdeki ölü yakımı uygulamasını çelişkili bulduğunu belirterek, bunu "Ĕger ki, çok eski dönemlere ya da belirli ama çok iyi tespit edilmiş bir bölgeye atfen değilse, Çinlilerin cesetlerin yakılmasına dair ifadeleri geleneklerle çelişmektedir” (Muzio, 2002, s. 126) şeklinde ifade etmiş̧tir. Bu durumda Muzio, arkeolojik olarak ortaya konulmuş bir durum ile çelişmektedir. J. P. Roux, Türklerde kesin olarak görülen ölü yakımının Hunlardan miras kalmadığını ifade eden ilim adamlarındandır (Roux, 2011, s. 275). Noin-Ula kurganlarında ölü yakımına tesadüf edilmemesi bu uygulamanın Hunlar arasında kısmen de olsa uygulandığ gerçeğini değiştirmez. Çünkü Hun dönemine ait Kazakistan bozkırında tespit edilen Novonikol, Kenes, Berlik ve Yavlenka Hun-Sarmat mezarlarında kremasyon izlerine tesadüf edilmiştir (Botalov, 2007, s. 101) ${ }^{6}$. Bunun gibi örnekleri Türklerin yayıldıkları saha boyunca genişletmek mümkündür.

Ölü yakımı uygulaması devlet yöneticilerine de uygulanmış, bu durum tarihi kaynaklara da kaydedilmiştir. Yeni Tang Kitabı 140a'ya göre Doğu Türkleri Kağanı Heyli Çinliler tarafından esir alındıktan sonra 634 yılında ölmüş ve öldükten sonra göçebelerin âdetine göre yakılıp külleri Ba Irmağı'nın sol tarafına dökülmüştür (Biçurin, 1950, s. 256). Heyli'nin de bir kağan olarak yakıma tabi tutulması, bazı kremasyon uygulanmış mezarların envanter bakımından zengin olması, bu mezarlardaki maddi kültür unsurunun Türklere ait olduğunun tespiti sonrasında Türklerin elit kesimine kremasyon uygulamasının yapıldığı fikrinin ortaya konulmasına sebep olmuştur. $\mathrm{O}$ halde ölü yakımın bulunduğu mezarların nispeten az olması, kremasyon uygulamasının toplumun her kesimine tatbik edilir bir uygulama olmadığını göstermektedir. D. G. Savinov, her türlü barbarizasyona rağmen bu uygulamanın Türklerin elitlerinde korunduğunu ifade etmiştir (Savinov, 2004, s. 57).

\footnotetext{
${ }^{5}$ Söz konusu müverrihler ölü yakımını tamamen kabul etmeseler de Türklerin ölü yakımı uygulamalarını terk etme sebebi olarak toplum yapısındaki çok parçalı etnik karakterin olmasına bağlamaktadırlar.

${ }^{6}$ Ayrıca Güney Zaural bölgesindeki Hun-Sarmat dönemine ait kremasyon uygulanan mezar çukurlarında, mezar dolgusunda sabit közler, yanmış kalıplar ve küller tespit edilmiştir. Ayrıntılı bilgi için bkz. E. O. Şimanskiy, "Kurganı s Ognennım Ritualam Yujnogo Zauralya (Gunno-Sarmatskoye Vremya)", Materialı XLVII Regionalnoy (III. İ vserossiyskoy s mejdunarodnım uçastiem) arheologoetnografiçeskoy konferentsii studentov i molodıh uçenıh Sibiri i Dalnego Vostoka (3-7 Aprelya 2007), Novosibirsk, 2007, s. 130
} 
Yazılı kaynaklarda ölü yakımı uygulaması açıkça zikredilmiştir. Buna göre kremasyon uygulaması Göktürkler dönemi için Çin kaynaklarında "Ölülerin yakıldı ğı, küllerinin gömüldüğü, ölülerin yakılmak için uygun zamanı beklediği” ve "uğurlu bir gün seçip ölüyü bindiği ata bindirip gündelik kullandı̆̆ eşyalarla beraber yakarlar, küllerini toplayıp uygun bir zamanda gömerler" (Gan, 2000, s. 363; Kapusuzoğlu, 2015, s. 510) ifadeleri ile karşımıza çıkmakta ve ölüler yakıldıktan sonra "küllerin gömülme işi eğer ölüm ilkbaharda veya yazın gerçekleşmişse otlar ve yapraklar sararınca, sonbaharda veya kışın olmuşsa bitkilerin büyüyüp açması beklenirdi ve küllerin gömülmesinden sonra taşları üst üste ylğarak tepesine bir direk dikerlerdi (Diyarbekirli, 1953, s. 56) şeklinde tasvir edilmektedir. Arkeolojik buluntular bakımından Türklere ait ölü yakımı ve sonrasında gömme uygulamasının uygulandığı mezarlara Tuva, Altay, Moğolistan, Kazakistan ve Yenisey havalisinde rastlanmıştır (Graç, 1968, s. 212).

Şekil 1. Tuva Khachy-Khovu'da Türklere ait ölü yakımı tespit edilmiş mezar çizimi

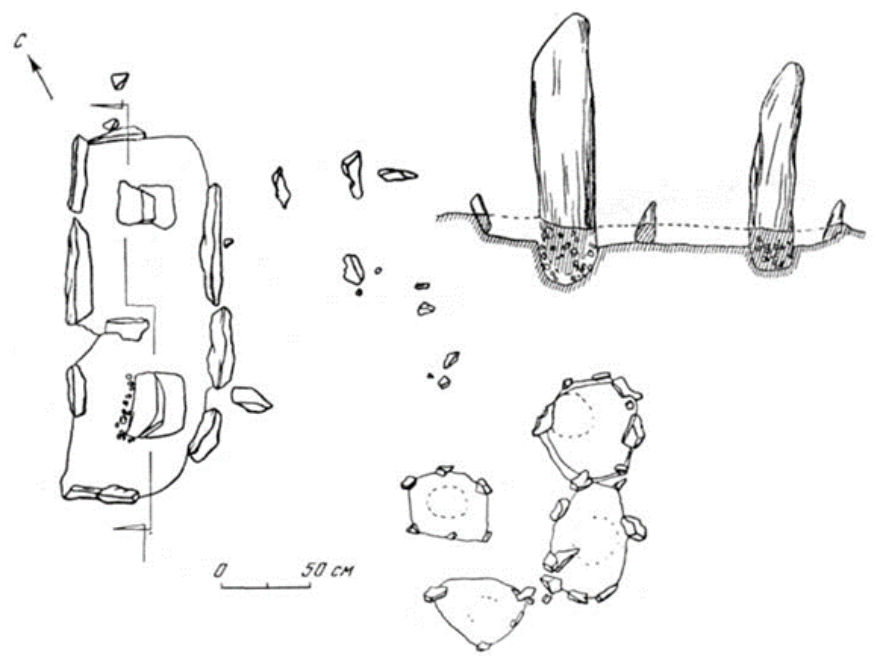

Kaynak: (Graç, 1968, s. 209.)

Hudyakov her ne kadar Türklerdeki ölü yakımı meselesine şüphe ile bakılması gerektiğini ifade etmiş olsa da kremasyon uygulamasının bulunduğu Türk mezarlarından birini bizzat kendisi kazmıştır. Hudyakov tarafından IX.-X.yy'a tarihlendirilmiş Yenisey Havzası'ndaki Türk dönemine ait Tepsey III kurganındaki 9 numaralı mezar kremasyon yapılmış atlı mezardır (Savinov, 2004, s. 37). Atlı kremasyon yapılmış bir Türk mezar örneğine Doğu Kazakistan Yukarı İrtiş boyunda Zevakin'de tesadüf edilmiştir. Söz konusu ölü yakımı mezar dışında gerçekleşmiş ve kalıntılar envanterle birlikte mezara bırakılmıştır. Bu mezardan insan iskelet kalıntıları ve 2 adet at kafatası elde edilmiştir (Arslanova,1972:57). Tıpkı kaynakların ifade ettiği gibi ölü yakıma tabi tutulmuş ve ardından kalıntıları mezara konulmuştur. Böylece arkeolojik buluntu ile kaynakların ifadesi birbirini doğrulamıştır.

M.Ö 3. yy’a ait Çin kaynaklarında Hunların "ölülerini iki katlı tabuta koyarak gömdükleri" (Karamürsel, 2002, s. 77) zikredilmiş olsa da yukarıda da ifade edildiği üzere arkeoloji çalışmaları sonucunda Hun kurganlarında kremasyon izleri tespit edilmiştir. Bu uygulamanın ilerleyen dönemlerde terk edildiği de yine Çin kaynaklarında zikredilmektedir. Bu durum "bir zamanlar ölülerini yakma alışkanlı̆̆ında olan Türkler, şimdi onları toprağa gömüyor ve mezar dikiyorlar" şeklinde kaydedilmiştir (Roux, 2001, s. 274).

Kremasyon uygulaması Orhun Abidelerinde adları zikredilen (Ergin, 2009)7, esas anayurtları Kögmen Dağları'nın kuzeyi ve Yenisey'in kollarından Kem Havzası olan Kırgızlarda ve Baykal çevresini yurt tutan Kurıkanların mezar geleneklerinde bulunmaktadır. Baykal

${ }^{7} \mathrm{KT}$, doğu, 4-BK, Doğu, 5. 
çevresinde VI.-X. yy. arasına tarihlendirilen ve Yassı Taş Mezar Kültürü içine dâhil edilen; Kurıkanlara ait çadır şeklindeki mezarlarda istikrarlı bir şekilde kremasyon yapıldığına dair örnekler mevcuttur (Aseev,1980, s.180, Etnogenez, 2010, s. 110). Xin Tang Shu'da Kırgızların ölülerini yakıp, ertesi yıl kemiklerini toplayarak gömdüklerinden bahsedilmektedir (Eberhard, 1996, s. 69). Ölü yakımı ritüeli "Biri ölünce yüzlerini kesmezler. Sonra ceset yakılır, külleri ve kemikleri bir yıl sonra toprağa gömerler" şeklinde betimlenmiştir (Taşağıl, 2004, s. 5). Kırgızlara ait ölü yakımının uygulandığı en geniş kurganlara Tuva'da bulunan Tora-Tal-Artı mezarlığında tesadüf edilmiştir. IX. ve X. yy.'a tarihlenen mezarların Tuvayı hâkimiyetleri altına alan Kırgız savaşçılarına ait oldukları ifade edilmektedir (Neçeva, 1966, s. 141).

Bu durumda Türklerde açıkça görülen kremasyon uygulamasının Türklerinde yüz yıllarca meskûn oldukları Orta Asya coğrafyasındaki en erken uygulanma döneminden itibaren ve Türklerle bağlantılarını ortaya koyarak ifade etmeye çalışalım:

\section{En Erken Dönemden İtibaren Kremasyon'a Bakış}

Bu uygulamanın Türk tarihi ve kültüründe bir yeri olduğu açıtır ve yukarıda delilleri ile kısaca ortaya konulmuştur. Orta Asya coğrafyasında ölü yakımı uygulamalarının en erken ne zaman görüldüğü meselesini açıklığa kavuşturmak için öncelikle Neolitik dönemden başlamak icap etmektedir. Bu bakımdan ilk önce Güney Sibirya Yenisey havalisi ve Altaylarda hâkim bir kültür dönemi olan ve Neolitik veya Eneolitik döneme ait olup olmadığı tartışmaları süren, evropoid bir ırkın temsil ettiği Afanasyevo Kültürü döneminden başlamak uygundur. Tüm Yenisey Havalisi, Rusya-Çin ve Moğolistan Altayları boyunca yayılmış ve yerel formlarının da olduğu düşünülen ${ }^{8}$ Afanasyevo Kültürü'nde kremasyon uygulaması tatbik edilmemiştir (Vadetskaya, Polyakov ve Stepanova, 2014, s. 221). Söz konusu dönemde ölü yakımı uygulamasının varlığına yönelik algı Kiselev'in sadece 2 yanık kemik bulması üzerine oluşmuştur (Kiselev, 1951, s. 29). Bunun dışında Afanasyevo geleneğinde kremasyon izlerine tesadüf edilmemiştir.

Güney Sibirya dairesi boyunca geniş açıdan meseleye bakmak gerekirse Baykal Gölü çevresinde hâkim olan kültür dönemlerinde kremasyon uygulaması mevcuttur. Bölgede kremasyon uygulamasının görüldüğü kültür dönemlerinin başında Serov Kültürü gelmektedir (Çirkin, 2019, s. 39). Fakat Serov Kültürü’nün tüm Güney Sibirya boyunca etkili olmadığı göz önünde bulundurulursa, Baykal çevresinde etkin olmuş bir dönem olarak kremasyon uygulamasının geniş olarak tüm bölgeyi etkisi altına alabileceği bizce mümkün görünmemektedir çünkü bu etki sadece yayılmacı, daha baskın taşıyıcılar tarafından gerçekleştirilebilirdi. Afanasyevo kültürü sonlarına doğru bölgeye gelen ve Afanasyevo dönemine eş zamanlı olarak; onun kadar erken döneme tarihlenemese de aynı dönemde aynı topraklarda yaşadığ bilinen ve Afanasyevo toplumunu kendi içinde eriten veya göçe tabi tutan Okunevo (M.Ö. II. bin yıl) toplumuna ait kültür dönemi görülmektedir. Oldukça büyük ebatlardaki stelleri ile meşhur olan Okunevo toplumunun mezarlarının tamamına yakınında inhumasyon uygulaması görülmekte olup, kremasyon yapıldığına dair az sayıda örnek mevcuttur (Çirkin, 2019, s. 98). Bölgede Okunevo Kültürü'nün hâkimiyetinin yükselişe geçtiği dönemde batıdan, en erken mezar ve yerleşim kalıntılarına Ural havalisinde ulaşılan Andronovo Kültürü toplumunun sızmaları başlamış ve Yenisey boyunca yayılmışlardır. Bu kez bu sahayı terk etmek zorunda kalanlar ise Mongoloid özellikleri bulunan Okunevo toplumu olmuştur. Savinov, İskit Kültürü’nün temelini atanların Tuva'ya çekilen Okunevo ahalisinin olduğunu iddia etmektedir (Savinov, 2004, s. 115).

Batıdan doğuya doğru Kazak Bozkırı boyunca Altay ve Tanrı Dağları sistemi ve Yenisey havalisine giriş yapıp, doğuda en son Yenisey havalisini meskûn tutan ve antropolojik olarak

\footnotetext{
${ }^{8}$ Bir kısım ilim adamı tarafından Çemurçek Kültürü Afanasyevo Kültürü'nün yerel bir formu olduğunu düşünürken bir diğer taraf ise özgün bir kültür olduğu ifade etmektedirler.
} 
Türklerle bağlantısı tespit edilmiş ${ }^{9}$, Evropoid Andronovo toplumunun mezar gömü geleneğinde kremasyon uygulaması bulunmaktadır. Türk tarihi ve Bozkır Kültürü'nün teşekkülü açısından büyük önem arz eden Srubna (Posrednikov ve Kravets, 1954, s. 384)-Andronovo (Alayeva, 2005, s. 283) Kültürü döneminde ölü yakımı ve sonrasında defin merasiminin gerçekleştirildiği arkeoloji çalışmalarıyla ortaya konulmuştur. Söz konusu döneme ait mezar kazı çalışmalarında ölü yakım işleminin mezar dıșında yapıldığı ve ardından kalıntıların mezara bırakıldığı tespit edilmiştir. Andronovo Kültürü mensuplarının Altay havalisi bozkır ve orman-bozkır alanlarında tespit edilen kremasyon tipi mezar gömü oranı \% 4'tür. Bu oranın \%0,6'sı çiftlere (karı-koca) ait mezarlardır. Bununla birlikte hem inhumasyon hem de kremasyon uygulanmış mezarlar vardır ki onların oranı da \%0,7'dir (Fedoruk, 2017, s. 1072-1074) ${ }^{10}$. Batı Sibirya orman bozkır bölgesinde ise sonuçlar daha farklı oranlarda karşımıza çıkmaktadır. Baraba ovasının batısında \%90 inhumasyon-\%10 kremasyon uygulanırken, doğu kesiminde ise \%90 kremasyon-\%10 inhumasyon uygulaması yapılmıştır (Çirkin, 2019:119). Bu durum Andronovo Kültürü’nün farklı safhalarına ait olmalarından ileri gelmektedir. Lisakovsk mezarlığı örneğinden yola çıkacak olursak, aynı mezarlıktaki Andronovo Kültürü'nün Alakul (Kremasyon \%14-inhumasyon \%86) ve Federovo (kremasyon \%93-İnhumasyon \%7) safhalarının kremasyon ve inhumasyon verilerinin farklı olduğunu görebiliriz (Usmanova, 1991, s. 91). Bu durum toplumdaki elit, öncü bir gurubun varlığı ve bu uygulamanın ona aidiyeti durumuyla açıklanabilir.

Kazakistan coğrafyasında Andronovo halkı tarafindan ölü yakımı uygulaması Tunç Çağının son aşamasında artık büyük oranda bırakılmıştır ve yeni bir evreye geçilerek Begaz Dandıbay Kültürü vücuda getirilmiş fakat kremasyon uygulaması tamamen terk edilmemiştir. Yenisey havalisinde son zamanlarını yaşayan Andronovo kültürü Geç Tunç Çağı zamanında Karasuk Kültürü ile eş zamanlı olarak bölgede bulunmuştur. Gryaznov, Novojenov, Korenyako ve Çlenova gibi pek çok ilim adamı Andronovo Kültürü ve Karasuk Kültürü arasında devam niteliği bakımından ilişkiler bulunduğunu ifade etmişlerdir (Çlenova, 1983, s. 30; Gryaznov, 1952, s. 130; Korenyako, 1990, s. 28; Novojenov, 2013, s. 325). Bu ilişkiler özellikle Andronovo Kültürü'nün son dönemlerine ait mezarlarda, Begaz Dandıbay özellikli abidelerde görülmektedir.

Kiselev, Karasuk Kültürü dönemleri mezarlarında ölü yakımının bulunduğunu ve G. P. Sosnovskiy'nin 1927'de ve 1932'de geç Karasuk dönemine ait bir mezarda ölü yakımı uygulamasının izlerini bulduğunu bildirmektedir (Kiselev, 1951, s. 112). Karasuk Kültürü döneminin ardından ölü yakımı uygulamasına Tagar Kültürü'nde tesadüf edilmektedir. Vadetskaya, Tagar Kültürü'nün Erken Saragaş safhasının erken mezarlarında 10 ile 20 kişi arasında değişen kişilerin büyük mezarların mezar odalarına yerleştirildikten sonra "yerinde yakım" adı verilen uygulamanın yapıldığını belirtmektedir (Vadetskaya, 1986, s. 83). Bu tip uygulamalar Taştık Kültürü UybatÇaa-tas mezar örneğinde de tesadüf edilmiştir (Evtyuhova, 1948, s. 5; Vasilev, 2016, s. 31; Okladnikov, 1959, s. 40). Bununla birlikte Taştık Kültürü döneminde hem inhumasyon hem de kremasyon uygulaması mevcuttur. Taştık Kültürü'nün erken Batenev (I. IV. yy.) ve Tepsey (V.-VII. yy.) safhalarında her iki uygulama birlikte görülmektedir (Korneev, 2009, s. 164). Hatta bu dönemde mumyalama uygulaması da mevcuttur. Kazakistan'da VI.-VIII. Yy'a ait Türk mezarlarında ve Elantağ'da VIII.-X. yy'a tarihlendirilen mezarlarda kremasyon uygulamasının kullanıldığı, bu mezarların "bıyıklı kurganlar" olarak adlandırılan kurgan grubunun mezar yapı üslubu ile benzerlikler taşıdığı tespit edilmiştir (Botalov, 2007, s. 191). Bıyıklı kurganlar ise İssedon/Sakalara atfedilmektedir (Akiş̧ev-Kuşaev, 1963, s. 134) ve Kazakistan boyunca yayılan bu "Parlak Sakalar"ın ataları genetik ve kültürel açıdan Andronovo halkı ile özdeşleştirilmektedirler (Grakov, 2006, s. 302). Akişev ve Kuşaev Heredotos'un

\footnotetext{
${ }^{9}$ Erken Türk mezarlarından Arısi yakınlarındaki Şignak-Say’daki VI.-VII. Yüzyıl Kengeres mezarlarındaki yetişkin erkeğin Evropoid Andronovo tipinde, kadının ise Andronovo’ya yakın brakisefal tipte olduğu görülmektedir. Bkz. Ginzburg, V. V., "Materialı k Antropologii Drevnego Naseleniya Yujnogo Kazahstana”, SA XXI., Ed. A. Ya. Bryusov, Moskva-Leningrad, 1954 , s. 384.

${ }^{10}$ Yedisu Bölgesi Ası platosunda (M.Ö. XII-XI.) Kulsay, Turgen, Kızıl Bulak, Oy Jaylu'da bulunan aynı döneme ait mezarlarda hem inhumasyon hem de kremasyon uygulaması kullanılmıştır. Bkz. Hulio Bendezu Sarmiento, Pogrebalnıe Sorujeniya dlya Kremirovannıh Ostankov Epohi Bronzı v Semireçya (Kazahstane), Edit. H. B Sarmiento-P. Selye, Mejdunarodnıy İnstitut Tsentralno Aziatskih İssledovanii/UNESCO, Semerkant/Paris, 2013, s. 123.
} 
Aristeas'tan naklen verdiği bilgilere göre İssedonları Çin kaynaklarında zikredilen Wu-sunlarla ${ }^{11}$ eşleştirmektedirler (Akişev ve Kuşaev, 1963, s. 18). Yaşar Çoruhlu da bu dönemin Hsiug-nu devrine giriş olarak ifade etmektedir (Çoruhlu, 2016, s. 188). Bir diğer görüşe göre ölü yakımı âdeti Wu-sunların yayılmış oldukları sahada Kimeklerin ${ }^{12}$ yönetici tabakasına ve Türk Kültürü’nün kuvvetle etkisi altında kalmış Samoyedlere bağlanmaktadır (Balınt, 1986, s. 22).

\section{Sonuç ve Öneriler}

Sonuç olarak en erken dönemden itibaren Orta Asya coğrafyasında kremasyon uygulaması mevcut olup en geniş yayılım sahasına ve uzun soluklu bir tarihi periyoda hâkim bir kültür dönemi olan Andronovo Kültürü döneminden Türklerin tarih sahnesine çıkışına kadar izleri takip edilen Karasuk Kültürü, Tagar ve Taştık Kültürü, İskitler, Hunlar ve nihayetinde Türklerde ölü gömü ritüelleri arasında kremasyon/uygulanmıştır. Türklerle antropolojik ve kültürel bağları sebebiyle bu uygulamanın Andronovo Kültürü döneminden kaldığını düşünmekteyiz. Bu uygulama Andronovo Kültürü döneminde yüksek oranlarda kullanılmasına rağmen her mezarda kullanılmamıştır. Türklerde de kremasyon uygulaması olmasına rağmen bu uygulama her kişi için uygulanmamıştır. Kaynaklarda bu uygulamanın Heyli gibi bir kağana ve arkeolojik kazılar sonucu Kırgız askeri beylerine ait olduğu düşünülen gruba uygulanmış olması. Bu uygulamanın toplumun elit kesimine uygulandığ fikrinin ortaya çıkmasına sebep olmuştur. Yukarıda da belirtildiği üzere toplumlar arasında mezar gömü üslubunda farklılıklara gidilebileceği belirtilmiştir. Bu duruma göre ölü gömme ritüelleri arasında farklı uygulamaların aynı kronolojik dönemde olsalar bile tercih edile bilinir. Misal olarak Andronovo Kültürü dönemlerinin erken safhalarında ölü yakımı uygulaması yaygın olarak kullanılırken aynı döneme ait mezarlarda inhumasyon uygulamasının yapıldığı da görülmektedir ${ }^{13}$.

Hint Avrupalılara atfedilmek istenen Andronovo Kültürü'nde ateş ve güneş kutsaldı ve bunun izleri ölü yakımı olarak mezar gömü üslubuna yansımıştır. Türkler Gök Tanrıya inanıyorlardı fakat ateş Türkler için kutsaldı ve onun kutsallığı hem Çin kaynakları hem Arap kaynakları hem de Bizans kaynaklarından Theophylaktos Simokatta tarafından nakledilmiştir. Ateşin eski her şeyi temizlediği ve kötü ruhları kovduğu inancı oldukça önemlidir. Bu anlayış özellikle İslam coğrafyacılarının kaynaklarında zikredilmektedir. Ateşe kutsallık atfeden Türklerin ataları olarak gördüğümüz, antropolojik olarak da Türklerle bağlantıları olan Andronovo Kültürü toplumu kremasyon geleneğini Türklerin yurt tuttuğu coğrafyaya getirmiş ve torunları olan Türk boylarına kısmen de olsa bu geleneğin geçmesine sebep olmuşlardır.

\section{Kaynakça}

Akişev, K. A. - Kuşaev, G. A. (1963). Drevnyaya Kultura Sakov i Usuney Reki ili. Alma-Ata.

Alayeva, İ. P. (2005). Obryad Truposojjeniya v Pogrebalnıh Pamyatnikah Srubno-Alakulskoy Kontaktnoy Zonı Yujnogo Zauralya. Voprosu Istorii i Arheologiyi Zapadnogo Kazahstana, Vip. 4, Uralsk.

Arslanova, F. H. (1972). Kurganı s Truposojjeniem v Verhnem Priİrtişe. Poiski i Raskopki v Kazahstane, Alma-Ata: 56-76.

\footnotetext{
${ }^{11} \mathrm{Wu}$-sunların etnik kimliği üzerine ilim adamları tarafindan farklı görüşler dile getirilmiştir. Bu görüşler arasında onların İndoGermenler topluluğu mensubu olduğunu savunanlar olduğu gibi, kullandıkları unvanlar, yaşam tarzları vb. sebeplerle Türk olduklarını iddia eden ilim adamları da mevcuttur. Bkz. İlhami Durmuş, "Vusunlar", Türkler, Ankara, 2002, s. 788. Ögel ise kesin bir ifade ile Wu-sunların Hsiug-nuların yani Hunların mensup oldukları ırk ve kültürden olduklarını belirtmektedir. Bkz. Bahaeddin Ögel, "Çin Kaynaklarına Göre Wu-sun'lar ve Siyasi Sınırları Hakkında Bazı Problemler", Ankara Üniversitesi Dil Tarih Coğrafya Fakültesi Dergisi, Cilt 6, Sa:4, 1948, s. 278.

12 IX. ve X. yy'da İrtiş boylarında yaşamış bir Türk kavmi bkz. Faruk Sümer, "Kimek”, TDV İslam Ansiklopedisi, C. 26, Ankara, 2002, s. 25-26.

${ }^{13}$ Yedisu Bölgesi Ası platosunda (M.Ö. XII-XI.) Kulsay, Turgen, Kızıl Bulak, Oy Jaylu'da bulunan aynı döneme ait mezarlarda hem inhumasyon hem de kremasyon uygulaması kullanılmıştır. Bkz. Hulio Bendezu Sarmiento, Pogrebalnıe Sorujeniya dlya Kremirovannih Ostankov Epohi Bronzı v Semireçya (Kazahstane), Edit. H. B. Sarmiento-P. Selye, Mejdunarodnıy İnstitut Tsentralno Aziatskih İssledovanii/UNESCO, Semerkant/Paris, 2013, s. 123.
} 
Aseev, İ. V. (1980). Pribaykalye v Sredniye Veka (Po Arheologiçeskim Dannım). İzdatelstvo Nauka, Novosibirsk.

Biçurin, N. Y. (1950). Sobraniye Svedeniy o Narodah, Obitavşih v Sredney Azii v Drevniye Vremena. T. I, Moskva-Leningrad.

Binford, L. R. (1971). Martuary practises: Their study and their potential/approaches to the social dimensions of martuary practices. Memory Of The Society For American Archeology, 25, 629.

Botalov, S. G. (2007). Gunnı i Tyurki (İstoriko-Arheologiçeskaya Rekonstruktsiya). Çelyabinsk.

Csanat, B. (1986) VI.-VIII. yüzyıllarda iç Asya ve Orta Asya'daki Türk tipi arkeoloji anıtları. Türk Kültürü Araştırmaları Enstitüsü, 24(1), 7-32.

Çirkin, S. (2019). Güney Sibirya arkeolojisi ve Şamanizm. İstanbul: Yap1 Kredi Yay.

Çlenova, N. L. (1983). Osnovi Hronologii Andronovskih Pamyatnikov Federovskogo Tipa. Bronzoviy Vek Stepnoy Polosı Uralo-İrtişskogo Mejdureçya, Edit. N. Ya. Merpert-G. B. Zdanoviç, 22-35.

Çoruhlu, Y.(2004). Eski Türklerde ölüm. Cogito, 40, 244-268.

Çoruhlu, Y. (2016). Eski Türklerin kutsal mezarları Kurganlar. İstanbul: Ötüken Yay.

Eberhard, W. (1996). Çin'in Şimal komşulart. (N. Uluğtuğ, Çev.). Ankara: TTK.

Ergin, M. (2009). Orhun Abideleri, İstanbul: Boğaziçi Yay.

Etnogenez i Kulturogenez v Baykalskom Regione (Srednevekovye), (2010). Edit. P. B. Konovalov, Ulan-Ude.

Evtyuhova, L. A. (1948). Arheologiçeskiye Pamyatniki Yeniseyskih Kırgızov (Hakasov), Abakan.

Diyarbekirli, N. (1953). Türklerde mezar yapısı ve defin merasimi. Türk Kültür Araştırmaları Prof. Dr. Muharrem Ergin'e Armağan, Ankara: 53-61.

Duranlı, M. (2018). Saha Türklerinde Şaman mezarları ve bu mezarlarla bağlantılı anlatılar. Muvaffak Duranl1- Ramazan Kemal Haykıran (Ed), I. Uluslararası Türk İslam Mezar Taşları Kongresi Bildiriler Kitabı, (207-213). Aydın.

Durmuş, İ. (2002). Vusunlar. Türkler, Ankara: 782-788.

Durmuş, İ. (2004). İskitlerde ölü gömme geleneği. Milli Folklor, 61, 21-29.

Fedoruk, O. A. (2017). Pogrebalnıy Obryad Andronovskoy Kulturı na Territorii Stepnogo i Lesostepnogo Altaya: Osnovnı Harakteristiki. V (XXI) Vserossiyskii Arheologiçeskii Syezd, Barnaul, 1072-1074.

Grakov, B. N. (2006). İskitler. (A. Batur, Çev.). İstanbul: Selenge Yay.

Heredotos, (2004). Heredot Tarihi. (M. Ökmen, Çev.). İstanbul: İş Kültür Yay.

Gan, L. (2000). Göktürklerde gelenekler ve dini inançlar. (E. Sarıtaş Çev.). Türk Dünyası Incelemeleri Dergisi, IV, 361-374.

Ginzburg, V. V. (1954). Materialı k Antropologii Drevnego Naseleniya Yujnogo Kazahstana. SA XXI., Ed. A. Ya. Bryusov, Moskva-Leningrad: 379-396.

Graç, A. D. (1968). Drevneyşiye Tyurkskiye Pogrebeniya s Sojjeniyem v Tsentralnoy Azii. Ístoriya, Arheologiya i Etnografiya Sredney Azii, Moskva. 
Gryaznov, M. P. (1952). Pamyatniki Karasukskogo Etapa v Tsentralnom Kazahstana. SA XVI, Edit, M. İ. Artamanov, Moskva: 129-163.

Hudyakov, Yu. S. -Koçaev, B. A. (1997). Drevnetyurkskiye Mumifitssirovannoye Zahorenneye v Mesnosti Çatır u s. Jana-Aul v Gornom Altaye. Humanitarnıe Nauki v Sibiri, 3, 10-18.

Hudyakov, Yu. S. -Tabaldiyev, K. Ş. (2009). Drevniye Tyurki na Tyan-şanye, Edit. V. İ. Molodin, Novosibirsk.

İbn Fazlan Seyahatnamesi, (1995). (R. Şeşen, Çev.). İstanbul: Bedir Yay.

Kapusuzoğlu, G. (2015). Çin kaynaklarına göre Türk kültür çevresinde evlenme ve cenaze gelenekleri. $T A D, 34(58), 507-522$.

Karamürsel, A. (2002). Türklerde mezar geleneği. Türkler, 3, Ankara.

Kiselev, S. V. (1951). Drevnyaya İstoriya Yujnoy Sibiri, İzdatelstvo Akademiyi Nauk SSSR, Moskva.

Korenyako, V. A. (1990). O Sotsiologiçeskoy İnterpretatsii Pamyatnikov Bronzovogo Veka (Pogrebeniya Dandıbay-Begazinskogo Tipa). SA, No:2, Ed. S. A. Pletneva, Moskva, 28-41.

Korneev, Yu. S. (2009). Pogrebalnıy Obryad Naseleniya Taştıkskoy Kulturı: Tipologiya i Lokalnıye Variantı Dlya Sklepov. Vestnik NGU, T.8, Vıp.5, 164-173.

Muzio, C. L. (2002) “Erken dönem Türklerinde defin işlemleri”, Türkler, C.3, Ankara.

Neçaeva, L. G. (1966). Pogrebeniya s Truposojjeniyem Mogilnika Tora-Tal-Artı. MoskvaLeningrad.

Novojenov, V. A. (2013). Drevneyşie Kuznetsı Evraziiskoy Stepi (Karasukskaya Kultura i Proishojdeniya Begazı-Dandıbayevskogo Fenomena. Dalalık Evraziyanın Begaz Dandıbay Medenieti, Edit. A. Z. Beysunov, Almat1: 321-329.

Okladnikov, A. P. (1959). Ancient population of Siberia and its culture. Published by Peabody Museum Cambridge Massachutes.

Ögel, B. (1948). Çin kaynaklarına göre Wu-sun'lar ve siyasi sınırları hakkında bazı problemler. Ankara Üniversitesi Dil Tarih Coğrafya Fakültesi Dergisi, 6(4), 259-278.

Ögel, B. (2003). İslamiyetten önce Türk kültür tarihi. Ankara: TTK.

Posrednikov, V. A.- Kravets, D. P. (1992). K Voprosu ob Obryade Krematsii u Srubnıh Plemen Donbassa. Donetskiy Arheologiçeskiy Sbornik, Vıp. 1, Donetsk.

Roux, J. P. (2001). Türklerin ve Moğolların eski dini. (A. Kazancıgil, Çev.). İstanbul: Kabalcı Yay.

Roux, J. P. (2011). Eski Türk mitolojisi. (M. Y. Sağlam, Çev.). Ankara: BilgeSu Yay.

Rudenko, S. İ. (1952). Dağllk Altay buluntuları ve Altaylar. (A. İsina, Çev.). Moskva-Leningrad: SSCB İlimler Akademisi Yay.

Sarmiento, H. B. (2013). Pogrebalnie Sorujeniya dlya Kremirovannih Ostankov Epohi Bronzı v Semireçya (Kazahstane), Edit. H. B Sarmiento- P. Selye, Mejdunarodnıy İnstitut Tsentralno Aziatskih İssledovanii/UNESCO, Semerkant/Paris.

Savinov, D. G. (2004). Naseleniya Srednego Yeniseya v Epohu Slojeniya Skotovodçeskih Obşetv (III. tıs. do. n.e.-seredina I tıs. n.e.). Journal Of Turkic Sivilization Studies, Bişkek: 107-133.

Sharaf Al-Zamān Tāhır Marvazī on China, The Turks and India, Arapça'dan İngilizceye tercüme ve açıklamalar. V. Minorsky, The Royal Asiatic Society, London: 1942.

Sümer, F. (2002). Kimek. TDV İslam Ansiklopedisi, C. 26, Ankara, 25-26. 
Şeşen, R. (2001). İslam coğrafyacılarına göre Türkler ve Türk ülkeleri. TTK, Ankara.

Şimanskiy, E. O. (2007). Kurganı s Ognennım Ritualam Yujnogo Zauralya (Gunno-Sarmatskoye Vremya). Materialı XLVII Regionalnoy (III. I vserossiyskoy s mejdunarodnum uçastiem) arheologo-etnografiçeskoy konferentsiistudentov i molodıh uçenıh Sibiri i Dalnego Vostoka (3-7 Aprelya 2007), Novosibirsk: 130-132.

Taşağıl, A. (2004). Çin kaynaklarına göre eski Türk boyları. Ankara: TTK Yay.

Usmanova, E. P. (1991). Andronovskiy Pogrebalnıy Obryad i Problema Hronologii i Periodizatsii. Problemı Hronologii i Periodizatsii Arheologiçeskkih Pamyatnikov Yujnoy Sibiri (Tezisı Dokladov k vse soyuznoy Nauçnoy Konferentsii 3-5 aprelya 1991), Barnaul, 9093.

Vadetskaya, E. B. (1986). Arkheologicheskiye Pamyatniki v Stepyakh Srednego Yeniseya. Nauka, Leningrad.

Vadetskaya, E. B. - Polyakov, A. V. - Stepanova, N. F. (2014). Svod Pamyatnikov Afanasevskoy Kulturl, Azbuka, Barnaul.

Vasilev, S. A. (2016). Taştıkskii Kompleks na Mnogosloynoy Stoynke Uy II v Zapadnom Sayana. Arheologiçeskiye Vesti 22, Edit. E. N. Nosov, Saint-Petersburg: 31-34.

Yaşa, R. (2019). Eski Türk cenaze törenlerinde ölü yakma adeti. Türk Tarihi Araşstrmaları Dergisi/Journal Of Turkish History Researches, Prof. Dr. Bahaeddin Ögel Saylsl, 4(1), 275295.

ETİK ve BİLIMSEL İLKELER SORUMLULUK BEYANI

$\mathrm{Bu}$ çalışmanın tüm hazırlanma süreçlerinde etik kurallara ve bilimsel atıf gösterme ilkelerine riayet edildiğini yazar(lar) beyan eder. Aksi bir durumun tespiti halinde Afyon Kocatepe Üniversitesi Sosyal Bilimler Dergisi'nin hiçbir sorumluluğu olmayıp, tüm sorumluluk makale yazarlarına aittir. 